\title{
Extraintestinal gastrointestinal stromal tumor of undetermined origin: Is the mass resection a wrong approach? A case report and review of the literature
}

\author{
Özgür Haki Yüksel, Serkan Akan, Çaglar Yildirim, Ahmet Ürkmez, Ayhan Verit \\ Fatih Sultan Mehmet Research \& Training Hospital, Dept. of Urology, Istanbul, Turkey
}

\begin{abstract}
Summary Gastrointestinal stromal tumor (GIST) was first defined by Mazur et al. in 1983. GIST is evaluated among tumoral lesions that can be acquired or congenital. Those not associated with gastrointestinal system are termed as extragastrointestinal stromal tumor (EGIST). EGISTs can develop on intraperitoneal spaces as omentum, mesenterium and gallbladder and they can occur on retroperitoneum, extraperitoneal (prostate) and intrapelvic organs. Herein, we present a case with EGIST in a 65-year-old male patient located in intrapelvic and retroprostatic area which had no connection with gastrointestinal system as assessed by radiological methods and we discuss its treatment. We reviewed the literature and observed that ours is the first case report on a patient in which the mass was only extirpated rather than performing radical surgery. He is still at the 2. year of his follow-up period without any disease recurrence.
\end{abstract}

KEY WORDS: Extragastrointestinal stromal tumor; Prostate; Mass extirpation.

Submitted 10 January 2015; Accepted 19 March 2015

\section{INTRODUCTION}

Interstitial cells of Cajal (ICCs) have been defined by Ramon Cajal nearly 120 years ago as primitive neurons of the intestines (1). Various studies have shown that ICCs are pacemaker cells which ensure control of peristaltism in the gastrointestinal system (GIS) (2). Presence of ICCs in the urinary system was firstly demonstrated in 1999 (3). In two separate studies performed by Exintaris and Shafik, the authors proposed the presence of spontaneous contractile activity in the stromal layers of the prostate of guinea pigs and dogs $(4,5)$. Similarly presence of c-kit positive staining interstitial cells in the human prostate has been shown (6). It has been demonstrated that these cells can be pacemaker cells triggering slow-wave spontaneous electrical activity. It has been also suggested that they can be responsible for the transport of glandular secretion from prostatic acinar cells into its major and minor ducts and finally into urethra (4). Herein, a case of EGIST located in retroprostatic area without any association with gastrointestinal system was discussed and evaluated in the light of the literature.

\section{Case report}

A 60 year-old male patient presented to the clinic of general surgery with complaints of epigastric pain, jaundice and difficulty in defecation. When radiological evidence of intrapelvic retroprostatic mass was found, he was referred to our clinic. He had undergone hypophysectomy 16 years before with the diagnosis of pituitary adenoma. His laboratory test results were as follows: hematocrit: $36 \%$, platelet count: $373.000 / \mathrm{mm}^{3}$, serum creatinine: $0.67 \mathrm{mg} / \mathrm{dL}$, total testosterone: $0.24 \mathrm{ng} / \mathrm{ml}$, prolactin: $0.8 \mathrm{ng} / \mathrm{ml}$, baseline cortisol: $9 \mathrm{mcg} / \mathrm{dL}$, total PSA < $0.01 \mathrm{ng} / \mathrm{ml}$. Decreased luteinizing hormone levels were detected, while T3, T4, follicle stimulating hormone and results of complete urinalysis were within normal limits. The patient was receiving daily doses of $0.1 \mathrm{mg}$ levothyroxine and $2.5 \mathrm{mg}$ bromocriptine. General physical examination revealed a slight rebound tenderness (Murphy's sign positivity). Scrotal examination revealed decreased bilateral testicular volumes. During digital rectal examination, a rectal fibrotic mass in the prostatic lodge that could be partially palpated and presumably extending up to the proximal part of the rectum was palpated. Magnetic resonance imaging (MRI) of the abdomen revealed a mass lesion measuring nearly $65 \times 68 \times 95 \mathrm{~mm}$ with a central cystic and necrotic area. This mass was located on the left posterolateral part of the prostate gland associated with a decrease in the prostatic volume and its post-contrast images demonstrated a space-occupying lesion with an intense contrast uptake (Figure 1). The lesion was adjacent to the left posterolateral wall of the bladder. Demarcation line between some part of the mass and layers of the bladder walls was disrupted and also the lesion extended to the mesorectum. The adipose tissue interposed between the lesion and the rectum was effaced and the mass compressed the rectum. Multiple reactive lymph nodes were observed in bilateral inguinal regions. Degenerative changes consistent with the patient's age were observed in bony structures, which did not suggest metastases. Report of the flexible colonoscopic examination performed by the department of gastroenterology denied the presence of a macroscopic mass lesion. Positron emission tomography (PET/CT) disclosed a left paramedian mass lesion with a soft-tissue density over the prostatic lodge with its largest 


\section{Figure 1.}

Magnetic resonance imaging of the mass lesion measuring nearly $65 \times 68 \times 95 \mathrm{~mm}$.

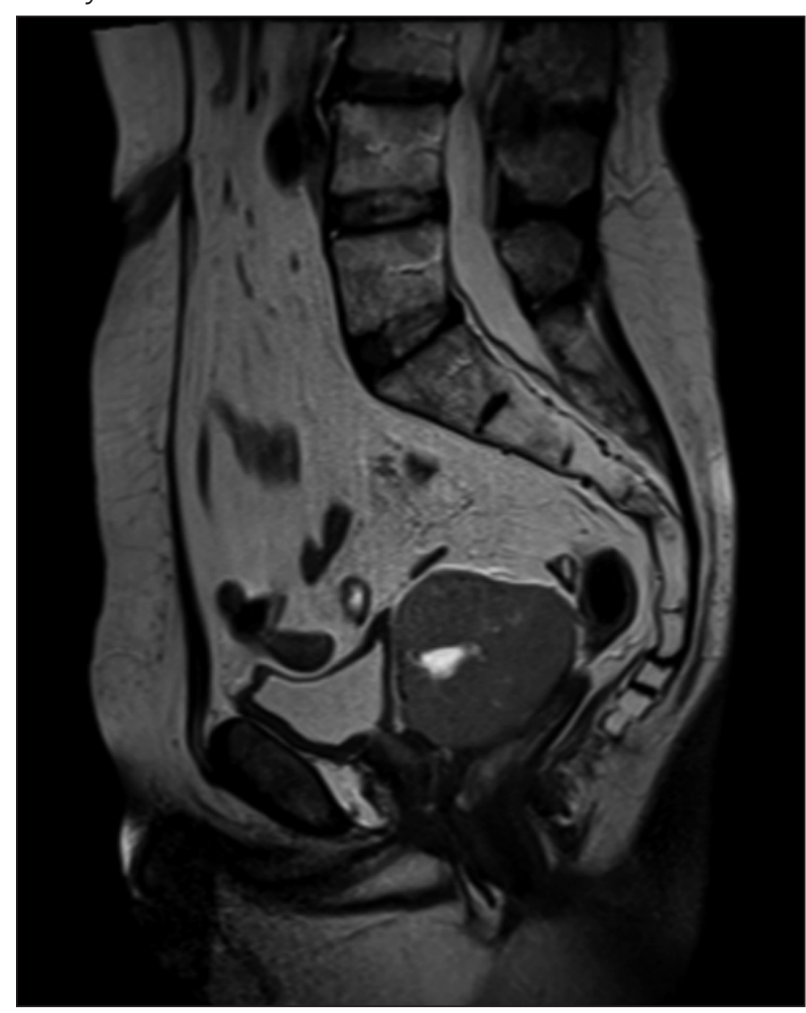

Figure 2.

Histopathological appearance of the mass lesion.

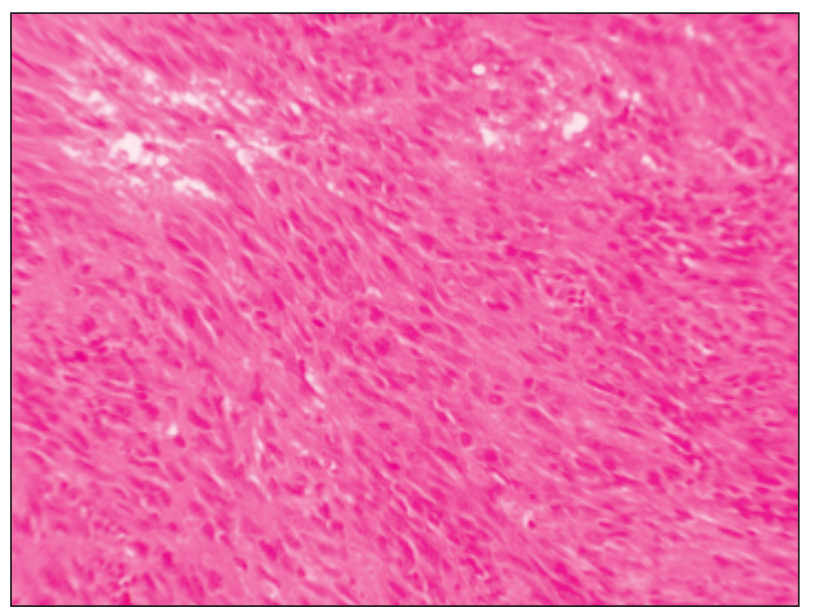

dimensions reaching 87 x $61 \mathrm{~mm}$. On PET/CT, effacement of fat planes interposed between the mass and the rectum posteriorly, and left obturator internus muscle laterally was observed.

The result of transrectal ultrasound guided biopsy was reported as gastrointestinal stromal tumor. With the aid of these data, surgical intervention was planned and realized under general anesthesia. Intraoperatively, a mass measuring nearly $8 \mathrm{~cm}$ posterior to the left side of the bladder without any association with genitourinary system and rectum was detected and resected as an intact mass from its suitable surgical cleavage and sent to pathology. pecimens excised from the anterior wall of the rectum and retroprostatic region were sent for frozen section evaluation. Frozen section examination was reported as tumor-negative, so we also excised tissues from surgical margin and sent them for histopathological examination.

Immunohistochemical evaluations of the specimen were reported as follows: CD-34, CD-117 (C-KIT), vimentin positive; S-100, desmin, SMA, HHF-35, panceratinine negative and Ki-67 score was 11-12\%.

Histopathological and immunohistochemical findings were evaluated as high-risk malignant gastrointestinal stromal tumor (Figure 2).

Postoperatively, imatinib treatment was planned. At 2 year follow-up period no radiologically detected metastasis was observed.

\section{Discussion and supplementary references are posted} on www.aiua.it

\section{REFERENCES}

1. Cajal SR. Sur les ganglions et plexus nerveux d'intestin (Abstract). CR Soc Bio. 1893; 5:217-223.

2. Rumessen J, Thuneberg L. Pacemaker cells in the gastrointestinal tract: interstitial cells of Cajal. Scand J Gastroenterol. 1996; 216:82-94.

3. Klemm MF, Exintaris B, Lang RJ. Qdentification of the cells underlying pacemaker activity in the guinea-pig upper urinary tract. J Physiol. 1999; 519:867-884

4. Exintaris B, Klemm FM, Lang JR. Spontanous slow wave and concractile activity of the guinea pig prostate. J Urol. 2002; 168:315-322.

\section{Correspondence}

Özgür Haki Yüksel, MD (Corresponding Author)

ozgurhaki@gmail.com

Serkan Akan, MD

Çaglar Yildirim, MD

Ahmet Ürkmez, MD

Ayhan Verit, MD. Prof,

Dept. of Urology, Fatih Sultan Mehmet Research \& Training Hospital Içerenköy/Ataşehir Tr- 34752 Istanbul, Turkey 